\title{
Novel Bioactive Glass Putty (S53P4) as Bone Graft Expander in Minimally Invasive Lumbosacral Interbody Fusion
}

\author{
Ilkka Saarenpääa ${ }^{1,2}$, Jussi Hirvonen ${ }^{3}$, Jaakko Rinne ${ }^{1,2}$, Janek Frantzén ${ }^{1,2}$ \\ ${ }^{1}$ Department of Clinical Medicine, University of Turku, ${ }^{2}$ Division of Clinical Neurosciences, Department of Neurosurgery, Turku University \\ Hospital, ${ }^{3}$ Department of Radiology, University of Turku, Finland
}

Corresponding Author:

Janek Frantzén, MD

Division of Clinical Neurosciences, Department of Neurosurgery, Turku University Hospital, Hämeentie 11, Turku 20521, Finland

Tel: +358401305555

Fax: +35823133052

E-mail: janek.frantzen@tyks.fi

Received: February 19, 2018 Revised: September 25, 2018 Accepted: September 26, 2018
Objective: This study aimed to evaluate the clinically achieved interbody fusion rate in minimally invasive transforaminal lumbar interbody fusion (MI-TLIF) operations, when using a novel bioactive glass (BAG) S53P4 putty as bone graft expander together with local autologous bone (AB). A second purpose was to assess radiologically the subsidence of intervertebral cage into vertebral endplates. Methods: We conducted a retrospective analysis of 20 patients operated on with Ml-TLIF for 24 levels by a neurosurgeon in our clinic between 2014 and 2016. In addition to routine follow-up by static plain radiographs, the patients with special complaints were investigated with computed tomography (CT) and/or magnetic resonance imaging (MRI). An independent neuroradiologist analysed the interbody fusion by bridging bone criteria in CT scans and subsidence either in CT scans or in static plain radiographs. The patients were followed up to 12-24 months postoperative. Results: The interbody fusion rate of $95.8 \%$ could be defined based on CT analysis of the symptomatic patients. Of the eight symptomatic patients, one had interbody cage dislocation of $2-3 \mathrm{~mm}$ posteriorly, lucency around a sacral screw and breakage of the other sacral screw. No subsidence of cages was observed. No postoperative infections were detected. Conclusion: As bone graft expander, the novel BAG S53P4 putty provides at least as good interbody fusion results as the presently used bone graft expanders and enhancers with no observed subsidence or postoperative infections.

Key Words: Bone replacement materials, Minimally invasive surgery, Lumbosacral region, Spinal fusion

\section{INTRODUCTION}

The gold standard for achieving spinal fusion is still autologous iliac crest bone graft (ICBG), often associated with increased surgical time, postoperative pain, haematoma, infection, fracture of the ileum, neurovascular injury and cosmetic deformity ${ }^{12)}$. In addition to minimally invasive (MI) approaches, inadequate local bone graft volume is problematic in revisions after a prior spinal decompression procedure. In order to avoid all of the above-mentioned, a host of bone graft alternatives have been developed ${ }^{5,7,14,23-24)}$. Allografts possess minimal osteoinductive factors and lack osteogenic properties due to the processing to decrease antigenity ${ }^{5,23-24)}$. They pose a potential risk for transmission of diseases, and incorporate slower and less completely with decreased vascularization and osteoconduction than autografts ${ }^{23)}$.

As synthetic, ceramic-based bone graft expanders, bioactive glasses (BAGs) are osteoconductive and osteostimulative, but non-osteoinductive materials that bond to bone without an intervening fibrous connective tissue layer ${ }^{10,13,24)}$. They are composed mainly of silica, sodium oxide, calcium oxide and phosphates, and firstly form a hydroxycarbonate apatite layer on the surface of the bioactive glass, following initial dissolution ${ }^{9,13)}$. Subsequently, BAG-bone bond formation occurs in stages by adsorption of biological structures on the glass surface, inflammation and macrophage action, and thereafter attachment and differentiation of stem cells ${ }^{9}$. As osteostimulative materials, BAGs stimulate recruitment and differentiation of osteoblasts, and activate them to produce new bone as a consequence of ionic dissolution ${ }^{10,28)}$. Thereafter, generation and crystallization of bone matrix, and further bone growth occur more slowly than during the earlier stages". Lastly, due to resistant surface of BAGs to cell-mediated degradation, physico-chemical degradation is only limited to the outer layer of a BAG granule, where dissolution and re-precipitation occur ${ }^{21,36)}$. The rates of bioacti- 
vity and resorption of BAGs are dependent on the chemical composition, the surrounding $\mathrm{pH}$, the temperature and the surface layers on the glass ${ }^{24,35}$. BAG S53P4 putty used in this study consists of a total of $60 \%$ by weight bioactive glass and is a synthetic, osteoconductive and osteostimulative paste-like bone void filler that was found biocompatible in our recent study ${ }^{31)}$.

Although previous studies have been carried out on BAG S53P4 granules in spinal fusion surgery with promising results, no clinical studies with the novel BAG S53P4 putty in spinal applications have been reported ${ }^{6,20,30)}$. The primary aim of this study was to investigate the interbody fusion rate acquired with the mixture of BAG S53P4 putty and autologous local bone graft. Also, intervertebral cage subsidence is studied as well as radiological and clinical outcome.

\section{MATERIALS AND METHODS}

\section{Study Design}

A retrospective, single-surgeon and single-tertiary centre case study was undertaken to evaluate the novel, mouldable puttyform of BAG S53P4 as bone graft expander in an MI approach to transforaminal lumbar interbody fusion (TLIF) clinically. The enrolled patients had undergone unsuccessful conservative treatment of degenerative and/or postoperative back pain and/or radicular symptoms for at least a year before they were operated for lumbosacral MI-TLIF with BAG S53P4 putty as bone graft expander. This study was performed without contacting the patients. Permission from the hospital administration was obtained before the initiation of the study.

\section{Patient Population}

Twenty-one consecutive minimally invasive spinal (MIS) patients were included in the study. One of the twenty-one included patients died from an acute myocardial infarction nine days after the operation. The remaining twenty patients ( 13 female and 7 men) were operated on 24 lumbosacral levels with interbody fusions in the Department of Neurosurgery at Turku University Hospital between September 2014 and November 2016. One neurosurgeon (J.F.) operated on all patients. The mean age of the patients included was 49.3 years and five of them had previously undergone decompressive lumbosacral surgery. The patient demographics and perioperative diagnosis are presented in Table 1.

\section{Bone Graft Expander}

BAG S53P4 putty (BonAlive ${ }^{\circledR}$ putty; BonAlive Biomaterials Ltd., Turku, Finland) consists of 48 weight- $\%$ of osteostimulative calcium-phosphorous-sodium-silicate BAG S53P4 granules (size $0.5-0.8 \mathrm{~mm}$ ) mixed with 12 weight- $\%$ of spherical (BAG S53P4) granules (size $0.09-0.425 \mathrm{~mm}$ ) and 40 weight- $\%$ of a synthetic binder (mix of glycerol and three chain lengths of polyethylene glycols (PEGs)). The composition of the bioactive glass granules of BAG S53P4 putty is (by weight- $\%$ ): $\mathrm{SiO}_{2} 53 \%, \mathrm{Na}_{2} \mathrm{O} 23 \%$, $\mathrm{CaO} 20 \%$ and $\mathrm{P}_{2} \mathrm{O} 5$ 4\%. The binder serves as a temporary binding agent for the granules. The putty is provided as a premixed extrudable and mouldable, but cohesive material, packed in a syringe-like applicator and sterilized by gamma irradiation.

\section{Surgical technique}

All procedures were performed percutaneously on one side, and through a Wiltse's approach on the symptomatic side. A navigation reference was first fixed with a clamp to the iliac crest. Then, cannulated Viper ${ }^{\circledR}$ MIS extended tab screws (DePuy Synthes, Le Locle, Switzerland) or in one case Everest ${ }^{\circledR}$ MIS screws (K2M, Leesbury, VA, USA) were inserted percutaneously using neuronavigation based on intraoperative 3D imaging (StealthStation ${ }^{\circledR} \mathrm{S7}^{\circledR}$ Navigation System and O-arm ${ }^{\circledR}$ Imaging System, Medtronic Navigation, Louisville, CO, USA). Thereafter, a contralateral Wiltse's approach was used. Subsequent to inserting the cannulated screws, facetectomy and discectomy were performed. Endplates were prepared and the fusion beds of the polyetheretherketone (PEEK) InterFuse ${ }^{\circledR}$ T-cage modules (VTI, Minneapolis, MN, USA) were filled with the mixture of BAG S53P4 putty and AB chips. After packing the mixture of BAG S53P4 putty and $A B$ chips in the anterior disc space, and implanting of the cage, the rods were inserted, compression was applied and the set screws were tightened on both sides. 3D control imaging was performed, and a mixture of BAG S53P4 putty and $A B$ chips was implanted on the transverse processes of the symptomatic side after scraping to bleeding bone, before closure in layers. The operation time, volume of bleeding, perioperative complications and postoperative hospitalization time were recorded (Table 1).

\section{Radiological and Clinical Evaluation}

Preoperative lumbar magnetic resonance imaging (MRI) and dynamic (flexion/extension) plain lumbar spine radiographs were carried out routinely. Intraoperatively, a 3D flat panel scan was performed in order to verify the correct position of the implants. Static plain radiographs were performed when ambulatory and at 3, 12 and 24 months. Patients with specific complaints were further investigated with $\mathrm{CT}$ and/or MRI scans.

The resorption of the mixture of BAG S53P4 putty and AB was estimated by plain lumbar spine radiography on a three-point scale (Table 2) by an independent neuroradiologist (J.H.). In grade 1 , the columns containing the mixture of BAG S53P4 putty and $A B$ were still distinguishable, while in grade 2 only partly distinguishable and in grade 3 not at all distinguishable. On the CT studies, interbody fusion was defined as presence of intervertebral bridging bone, without having had a revision or evidence of instrumentation loosening and/or breakage ${ }^{11)}$. The same independent neuroradiologist assessed bridging bone on a four-point grading scale according to Table 3 . The levels meeting the criteria of grades I or II were considered as bridged, whereas grades III and IV were judged not bridged. Moreover, fusion 
of the posterolateral implants was rated based on the Bridwell fusion grading system primarily from CTs, and if not available, from plain radiographs ${ }^{2}$. The disc height was evaluated from available preoperative and postoperative images.

The clinical follow-up in the outpatient clinic was at 3 and 12 months postoperative, the 24 months follow-up was merely a personal telephone interview. The minimum follow-up time was 12 months. The clinical outcome was measured as presence of low back pain, radicular leg pain, motor deficit, paresthesia

Table 1. Patient demographic data, preoperative diagnosis and perioperative parameters

\begin{tabular}{|c|c|}
\hline \multicolumn{2}{|l|}{ Gender, n (\%): } \\
\hline Female & $13(65.0)$ \\
\hline Male & $7(35.0)$ \\
\hline Age, mean (SD) (years) & $49.3(8.5)$ \\
\hline $\mathrm{BMI}$, mean $(\mathrm{SD})\left(\mathrm{kg} / \mathrm{m}^{2}\right)$ & $29.0(5.5)$ \\
\hline Smoker, n (\%) & $3(15.0)$ \\
\hline Previous lumbar surgery, n (\%) & $5(25.0)$ \\
\hline \multicolumn{2}{|l|}{ Diagnosis per level, n (\%) } \\
\hline Degenerative spondylolisthesis & $7(29.2)$ \\
\hline Spondylolytic spondylolisthesis & $7(29.2)$ \\
\hline Degenerative disc disease & $3(12.5)$ \\
\hline Recurrent disc herniation & $2(8.3)$ \\
\hline Postoperative instability & $1(4.2)$ \\
\hline Other degenerative segmental instability & $4(16.7)$ \\
\hline \multicolumn{2}{|l|}{ Number of levels operated, n (\%) } \\
\hline Single & $20(83.3)$ \\
\hline Two & $4(16.7)$ \\
\hline \multicolumn{2}{|l|}{ Operated level, n (\%) } \\
\hline L2-3 & $1(4.2)$ \\
\hline L3-4 & $2(8.3)$ \\
\hline$\llcorner 4-5$ & $9(37.5)$ \\
\hline L5-S1 & $12(50.0)$ \\
\hline \multicolumn{2}{|l|}{ Height of cage (mm), n (\%) } \\
\hline 7 & $9(37.5)$ \\
\hline 8 & $7(29.2)$ \\
\hline 9 & $5(20.8)$ \\
\hline 10 & $3(12.5)$ \\
\hline \multicolumn{2}{|l|}{ Angle of cage $\left({ }^{\circ}\right), \mathrm{n}(\%)$} \\
\hline 0 & $11(45.8)$ \\
\hline 10 & $11(45.8)$ \\
\hline 20 & $2(8.3)$ \\
\hline Volume of BAG S53P4 putty, mean (SD) (mL) & $6.9(2.5)$ \\
\hline Bleeding, mean (SD) (mL) & $292(136)$ \\
\hline Operation time, mean (SD) (min) & $343(57)$ \\
\hline Hospitalization, mean (SD) (days) & $4.0(1.7)$ \\
\hline
\end{tabular}

n: Number, SD: Standard deviation, BMl: Body mass index. and instability symptoms, and according to Odom's criteria as excellent, good, fair or poor ${ }^{27)}$.

\section{Statistics}

Differences in resorption grades between two time points at a time were tested using the test of symmetry. The non-parametric Wilcoxon signed-rank test was used to measure the differences in disc heights before and after the operation. $p$-values less than 0.05 were considered statistically significant. Statistical analyses were carried out using SPSS system for Mac, version 24 (IBM Corp., Armonk, NY, USA).

\section{RESULTS}

Four patients were operated for two-level and 16 patients for single level Ml-TLF. A total of 24 MI-TLF levels were operated in twenty patients. The most common operated level was L5-S1 (half of patients). A total of $58.4 \%$ of patients had either degenerative spondylolisthesis or spondylolysis and -olisthesis. The mean intraoperative bleeding was $292 \mathrm{~mL}$ (standard deviation (SD): $136 \mathrm{~mL}$ ), the mean operation time $343 \mathrm{~min}$ (SD: $57 \mathrm{~min}$ ) and the mean hospitalization time 4.0 days (SD: 1.7 days). Perioperative parameters are presented in Table 1.

The achieved interbody fusion could not be reliably estimated from static plain lumbar spine radiographs. Instead, the resorption of the mixture of BAG S53P4 putty and AB chips was graded according to static plain radiographs (Table 2). At three months postoperative, the above-mentioned mixture was still distinguishable in the fusion bed columns of the cage in $58.3 \%$ of the levels, whereas only in $8.3 \%$ at 12 months and in 5.3\% at 24 months postoperative compared to immediate postoperative radiographs. In contrast, these columns were not distinguishable in $4.2 \%$ of the levels at 3 months, in $37.5 \%$ at 12 months and in $47.4 \%$ at 24 months postoperative, respectively (Table 4). The resorption was significantly more progressed in radiographs at 12 months compared with those at three months $(p<0.001)$, but not in radiographs at 24 months compared with those at 12 months ( $p=0.135)$.

If indicated on clinical monitoring in the follow-up visits, patients were investigated with $\mathrm{CT}$ and/or MRI scans. Totally, ten CT scans were done for eight patients at 1-18 months postoperative (mean: 10.3 months, SD: 6.0 months). All CT scans were judged to show bridging bone across the intervertebral space. According to bridging bone criteria (Table 3), five of the nine

Table 2. Grading for resorption of the mixture of BAG S53P4 putty and autologous local bone graft in plain radiographs

\begin{tabular}{cl}
\hline Grade & \multicolumn{1}{c}{ Definition } \\
\hline 1 & Graft columns distinguishable \\
2 & Graft columns partly distinguishable \\
3 & Graft columns not distinguishable \\
\hline
\end{tabular}

BAG: Bioactive glass. 
Table 3. Grading for fusion with bridging bone criteria in CT scans ${ }^{18)}$

\begin{tabular}{ll}
\hline \hline Bridging fusion grade & Definition \\
\hline I: definitely fused & $\begin{array}{c}\text { Clear robust trabecular bone within or around the cage with incorporation and remodelling. No } \\
\text { lucencies around the cage. } \\
\text { Patchy areas of possible bony bridging with bone formation within cage but still present hairline } \\
\text { II: probably fused }\end{array} \quad \begin{array}{c}\text { lucency. Biological material not fully remodelled and intercorporated. No lucencies around the cage. } \\
\text { around the cage. }\end{array}$ \\
III: probably not fused & $\begin{array}{c}\text { No bridging bone within or around cage, with only scant or complete absence remodelling and } \\
\text { intercorporation. }\end{array}$
\end{tabular}

CT: Computed tomography.
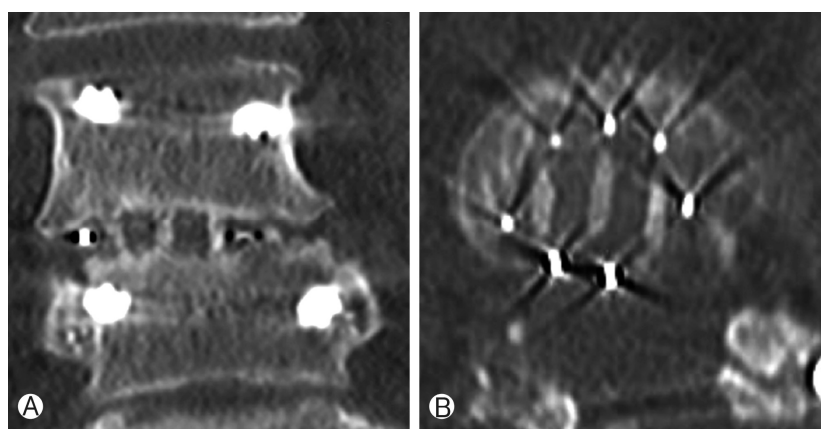

Fig. 1. Coronal (A) and axial (B) CT scans showing bridging bone (grade I) through fusion beds of the InterFuse ${ }^{\circledR}$ T-cage modules originally filled with the mixture BAG S53P4 putty and AB at 18 months postoperative.

investigated levels were graded as definitely fused (Fig. 1) and four levels as probably fused. The scans showing grade II (probably fused) were conducted at 1-18 months postoperative. One patient had cage dislocation of $2-3 \mathrm{~mm}$ posteriorly in static plain radiograph in $\mathrm{L} 5 / \mathrm{S} 1$-level at three months postoperative and lucency around a sacral screw and breakage of the other sacral screw in CT at nine months postoperative. This level was graded as probably fused with bridging bone criteria. A total of 15 patients $(75.0 \%)$ had posterolateral bone graft mixture unilaterally on the transverse processes and one bilaterally. Consequently, only one of the 17 levels showed Bridwell grade 1 fusion (fused with remodelling and trabeculae present), whereas the rest 16 levels were graded as Bridwell grade 4 (fusion absent with collapse/resorption of graft) in CTs and static plain radiographs at 12 months postoperative ${ }^{2)}$.

One patient had intervertebral cage subsidence/cage being inside the upper endplate and vertebral bone of $6 \mathrm{~mm}$ already in the intraoperative 3D flat panel scan. This subsidence remained unchanged until the latest follow-up radiograph at ten months postoperative. The mean disc height preoperatively was $6.3 \mathrm{~mm}$ (SD: $1.7 \mathrm{~mm}$ ) and postoperatively $7.9 \mathrm{~mm}$ (SD: $1.2 \mathrm{~mm}$ ) (Table 4). The median of difference of disc height was $1.0 \mathrm{~mm}$ greater postoperatively compared with that of preoperatively $(p<0.001)$.

Postoperatively, two patients presented with new radicular pain, one with new motor deficit and two with new paresthesia. In contrast, 14 patients found relief of low back pain and radicular
Table 4. Radiological outcome

\begin{tabular}{ll} 
Radiological follow-up time, mean (SD) (months) & $21.1(6.3)$ \\
Resorption grade at 3 months, $\mathrm{n}(\%)$ & $14(58.3)$ \\
1 & $9(37.5)$ \\
2 & $1(4.2)$ \\
3 & \\
Resorption grade at 12 months, $\mathrm{n}(\%)$ & $2(8.3)$ \\
1 & $13(54.2)$ \\
2 & $9(37.5)$ \\
3 & \\
Resorption grade at 24 months, $\mathrm{n}(\%)$ & $1(5.3)$ \\
1 & $9(47.4)$ \\
2 & $9(47.4)$ \\
3 & \\
Bridging fusion grade in CT & \\
(mean 10.3 months, SD 6.0 months), $\mathrm{n}(\%)$ & $5(55.6)$ \\
1 & $4(44.4)$ \\
2 & $0(0.0)$ \\
3 & $0(0.0)$ \\
4 & $6.3(1.7)$ \\
Preoperative dics height, mean (SD) (mm) & $7.9(1.2)$ \\
Postoperative dics height, mean (SD) (mm) & $1.2(1.5)$ \\
Change in disc height, mean (SD) (mm) & \\
\hline
\end{tabular}

n: Number, SD: Standard deviation, CT: Computed tomography.

pain, eight of instability symptoms, five of motor deficit, four of paresthesia. According to Odom's criteria, the patients' clinical outcome was described at the latest clinical follow-up visit as excellent or good in $65.0 \%$ of the patients and poor in $20.0 \%$ of the patients. Clinical outcome results are presented in Table 5.

\section{DISCUSSION}

The interbody fusion rate of this study is $95.8 \%$ with the mixture of BAG S53P4 putty and AB assuming that patients not fused would be symptomatic within 12 months. Fifteen pa- 
Ilkka Saarenpää, et al.

Table 5. Clinical outcome

\begin{tabular}{ll}
\hline \hline Clinical follow-up time, mean (SD) (months) & $19.0(7.6)$ \\
Low back pain, n (\%) & $14(70.0)$ \\
Relief & $0(0.0)$ \\
New & \\
Radicular pain, n (\%) & $14(70.0)$ \\
Relief & $2(10.0)$ \\
New & \\
Motor deficit, n (\%) & $5(25.0)$ \\
Relief & $1(5.0)$ \\
New & \\
Paresthesia, n (\%) & $4(20.0)$ \\
Relief & $2(10.0)$ \\
New & \\
Instability symptoms, $\mathrm{n}(\%)$ & $8(40.0)$ \\
Relief & $0(0.0)$ \\
New & \\
Odom's criteria, n (\%) & $8(40.0)$ \\
Excellent & $5(25.0)$ \\
Good & $3(15.0)$ \\
Fair & $4(20.0)$ \\
Poor & \\
\hline
\end{tabular}

n: Number, SD: Standard deviation.

tients completed two-year follow-up without hardware failure. Two patients with new postoperative radicular pain, one patient with new L5 motor weakness and two patients with new paresthesia were further investigated with lumbar spine CT and/or MRI. One patient suffering from new radicular pain, had a clear hardware failure, despite his interbody fusion having been graded as probably fused. The patient with new motor weakness had a new disc herniation in the lower operated level, but the symptom relieved with conservative treatment. In another patient, a new paresthesia, due to an adjacent level disc herniation was relieved with conservative treatment. In two patients, no explanation for radicular pain and paresthesia was found. No postoperative infections were detected.

A systematic review suggests $83.4-100 \%$ fusion rates for MlTLIF in degenerative spine, when using $A B$ or allograft with or without rhBMP-2 $2^{3)}$. In another systematic review, an average interbody bridging of $94.7 \%$ is presented for MI-TLIF with $A B$ or allograft with or without recombinant human bone morphogenetic protein-2 (rh-BMP-2) ${ }^{1)}$. By using a variety of different graft materials $(A B$, allograft cellular bone matrix, bone marrow aspirate, rh-BMP-2, corticocancellous chips, demineralized bone matrix (DBM)) alone or in combination in MI-TLIFs, interbody bridging was observed in $88 \%$ of the levels over 12 months and in $95 \%$ of the levels over 24 months $^{11)}$. In a recent meta-analysis, interbody bridging ranging from $91.8 \%$ to $99.1 \%$ was detected using combinations of $\mathrm{AB}$ with or without allograft and $r h-\mathrm{BMP}^{29)}$.
Interbody bridging of $96.6 \%$ and $92.5 \%$ were detected with and without rh-BMP, respectively ${ }^{29)}$. The lowest interbody bridging rate was seen with isolated use of local $A B(91.8 \%)$ and the highest by using local $A B$ with bone expander and rh-BMP $(99.1 \%)^{29)}$. Further, the highest interbody bridging rate without the use of BMP was achieved with local $A B$ and bone expander $(93.1 \%)^{29)}$.

When comparing the achieved arthrodesis rates in MI-TLIFs between the cohorts of local $A B$ and silicate hydroxyapatite ceramic bone graft expander (Actifuse ${ }^{\mathrm{TM}}$ ) or local $A B$ and rhBMP-2, a radiographical arthrodesis of $65 \%$ in the Actifuse cohort and $92 \%$ in the rh-BMP-2 cohort were achieved ${ }^{25)}$. Only in $26.7 \%$ of the levels solid fusion, in $34.1 \%$ indeterminate and in $38.6 \%$ inadequate fusion were assessed in PLIFs filled with $\beta$-tricalcium phosphate $(\beta$-TCP) and bone marrow aspirate (BMA) based on $\mathrm{CT}$ at 12 months postoperative ${ }^{32)}$. In another study, using $\beta$-TCP with a resorbable polymer (ChronOS ${ }^{\mathrm{TM}}$ Strip) together with BMA and local $A B$ in posterolateral fusion together with interbody support, interbody fusions of $54.1 \%$ and $71.2 \%$ were achieved in CTs at, respectively, 12 and 24 months postoperative ${ }^{15)}$. Interbody fusion rates of $84.6 \%$ and $92.3 \%$ were estimated for a type 1 collagen/hydroxyapatite $(\mathrm{HA})$ matrix $\left(\mathrm{Healos}^{\circledR}\right)$ with $B M A$, and $A B$, respectively, in PLIF from dynamic and static plain radiographs at 24 months postoperative ${ }^{26)}$. Furthermore, (1) $H A$ bone chip and local $A B$, (2) ICBG and local $A B$, and (3) local $A B$ groups were shown to have $91.7 \%, 92.9 \%$, and $94.6 \%$ fusion rates, respectively, in TLIFs evaluated by static plain radiographs at 12 months $^{16)}$. A mixture of local $A B$ and bioactive apatitewollastonite granules containing glass ceramic yielded solid fusion in $92.0 \%$ of TLF levels in static and dynamic plain radiographs at 6 months postoperative ${ }^{8)}$.

Subsidence of an interbody device in lumbar fusion is defined as sinking into one or both of the vertebral endplates, usually of $\geq 2-3 \mathrm{~mm}^{4,18)}$. As a result of loss of disc height, subsidence can result in partial loss of ligamentous stability, in the return of foraminal stenosis and ensuing nerve root stenosis ${ }^{19,33)}$. Particularly at the critical levels of L4/L5 and L5/S1, subsidence may also result in the loss of lordotic correction with consequent sagittal imbalance ${ }^{22)}$. In our study, no subsidence was detected. According to a prior MI-TLIF study using a PEEK cage, the rates of cage subsidence of $>2 \mathrm{~mm}$ and of $>4 \mathrm{~mm}$ were $14.8 \%$ and $6.6 \%$, respectively, at the last follow-up of $24-45$ months postoperative ${ }^{17)}$. The subsidence occurred in follow-ups on average at 7.2 months postoperative (SD: 8.5 months), and in all 1-25 months postoperative ${ }^{17)}$. In another study on TLIF, subsidence of $\geq 10 \%$ in $52.9 \%$ of the allograft spacer with adjuvant rh-BMP-2 group and in $12 \%$ of the allograft/DBM group were seen ${ }^{34)}$.

Only one of 17 levels of posterolateral bone graft mixture of BAG S53P4 and AB led to formation of solid bony fusion. This may be due to shortage of stress to the remodelling posterolateral bone because of the well-supporting and load-bearing framework of interbody cage, and later interbody fusion ${ }^{7)}$.

The main limitations of the current study are its retrospective nature and the lack of a control group. Also, the sample size was small. Assessing interbody fusion from plain radiographs 
was unreliable, but due to potential harm from ionizing radiation associated with $\mathrm{CT}$, these were restricted to symptomatic patients. Finally, pain, disability or other outcome scales, such as visual analogue pain scale or the Oswestry disability index, were not routinely in preoperative and postoperative use.

\section{CONCLUSION}

Novel BAG S53P4 putty as bone graft expander together with $A B$ provides at least comparable results with previously tested bone graft expanders and fusion enhancers in achieving lumbosacral interbody fusion without subsidence. A prospective, randomized controlled study is needed to further analyse particularly the clinical outcome.

\section{ACKNOWLEDGEMENT}

Dr. Saarenpää has received grants from Päivikki and Sakari Sohlberg Foundation and the Paulo Foundation.

\section{REFERENCES}

1. Bevevino AJ, Kang DG, Lehman RA Jr, Van Blarcum GS, Wagner SC, Gwinn DE: Systematic review and meta-analysis of minimally invasive transforaminal lumbar interbody fusion rates performed without posterolateral fusion. J Clin Neurosci 21:16861690, 2014

2. Bridwell KH, Lenke LG, McEnery KW, Baldus C, Blanke K: Anterior fresh frozen structural allografts in the thoracic and lumbar spine. Do they work if combined with posterior fusion and instrumentation in adult patients with kyphosis or anterior column defects? Spine 20:1410-1418, 1995

3. Chaudhary KS, Groff MW: Minimally invasive transforaminal lumbar interbody fusion for degenerative spine. Tech in Orthop 26:146-155, 2011

4. Chen L, Yang H, Tang T: Cage migration in spondylolisthesis treated with posterior lumbar interbody fusion using BAK cages. Spine 30:2171-2175, 2005

5. Fischer CR, Cassily R, Cantor W, Edusei E, Hammouri Q Errico $\mathrm{T}$ : A systematic review of comparative studies on bone graft alternatives for common spine fusion procedures. Eur Spine J 22:1423-1435, 2013

6. Frantzén J, Rantakokko J, Aro H, Heinänen J, Kajander S, Gullichsen E, et al: Instrumented spondylodesis in degenerative spondylolisthesis with bioactive glass and autologous bone: a prospective 11-year follow-up. J Spinal Disord Tech 24:455461, 2011

7. Grabowski G, Cornett CA: Bone graft and bone graft substitutes in spine surgery: current concepts and controversies. J Am Acad Orthop Sur 21:51-60, 2013

8. Hashimoto T, Shigenobu K, Kanayama M, Harada M, Oha F, Ohkoshi Y, et al: Clinical results of single-level posterior lumbar interbody fusion using the Brantigan I/F carbon cage filled with a mixture of local morselized bone and bioactive ceramic granules. Spine 27:258-262, 2002

9. Hench LL: The story of Bioglass ${ }^{\circledR}$. J Mater Sci: Mater Med
17:967-978, 2006

10. Hench LL: Genetic design of bioactive glass. J Eur Ceram Soc 29:1257-1265, 2009

11. Isaacs RE, Sembrano JN, Tohmeh AG, SOLAS Degenerative Study Group: Two-year comparative outcomes of MIS lateral and MIS transforaminal interbody fusion in the treatment of degenerative spondylolisthesis. Spine 41:S133-S144, 2016

12. Jakoi AM, Iorio JA, Cahill PJ: Autologous bone graft harvesting: a review of grafts and surgical techniques. Musculoskelet Surg 99:171-178, 2015

13. Jones JR: Review of bioactive glass: from Hench to hybrids. Acta Biomater 9:4457-2486, 2013

14. Kadam A, Millhouse PW, Kepler CK, Radcliff KE, Fehlings MG, Janssen ME, et al: Bone substitutes and expanders in spine surgery: a review of their fusion efficacies. Int J Spine Surg doi: 10.14444/3033, 2016

15. Kanter AS, Gandhoke GS, Welch WC, Arnold PM, Cheng JS, Okonkwo DO: A prospective, multi-center clinical and radiographic outcomes evaluation of ChronOS strip for lumbar spine fusion. J Clin Neurosci 25:36-40, 2016

16. Kim H, Lee C-K, Yeon J-S, Lee J-H, Lee K-H, Chang B-S: The efficacy of porous hydroxyapatite bone chip as an extender of local bone graft in posterior lumbar interbody fusion. Eur Spine J 21:1324-1330, 2012

17. Kim M-C, Chung H-T, Cho J-L, Kim D-J, Chung N-S: Subsidence of polyetheretherketone cage after minimally invasive transforaminal lumbar interbody fusion. J Spinal Disord Tech 26:87-92, 2013

18. Kumar A, Kozak JA, Doherty BJ, Dickson JH: Interspace distraction and graft subsidence after anterior lumbar fusion with femoral strut allograft. Spine 18:2393-2400, 1993

19. Le TV, Baaj AA, Dakwar E, Burkett CJ, Murray G, Smith D, et al: Subsidence of polyetheretherketone intervertebral cages in minimally invasive lateral retroperitoneal transpsoas lumbar interbody fusion. Spine 37:1268-1273, 2012

20. Lindfors NC, Tallroth K, Aho AJ: Bioactive glass as bone-graft substitute for posterior spinal fusion in rabbit. J Biomed Mater Res 63:237-244, 2002

21. Lindfors N, Koski I, Heikkilä J, Mattila K, Aho A: A prospective randomized 14-year follow-up study of bioactive glass and autogenous bone as bone graft substitutes in benign bone tumors. J Biomed Mater Res Part B: Appl Biomater 94B:157-164, 2010 22. Malham GM, Ellis NJ, Parker RM, Blecher CM, White R, Goss $\mathrm{B}$, et al: Maintenance of segmental lordosis and disc height in stand-alone and instrumented extreme lateral interbody fusion (XLIF). Clin Spine Surg 30:E90-E98, 2017

23. Miyazaki M, Tsumura H, Wang JC, Alanay A: An update on bone substitutes for spinal fusion. Eur Spine J 18:783-799, 2009

24. Nandi SK, Roy S, Mukherjee P, Kundu B, De DK, Basu D: Orthopaedic applications of bone graft \& graft substitutes: a review. Indian J Med Res 132:15-30, 2010

25. Nandyala SV, Marquez-Lara A, Fineberg SJ, Pelton M, Singh K: Prospective, randomized, controlled trial of silicate-substituted calcium phosphate versus rhBMP-2 in a minimally invasive transforaminal lumbar interbody fusion. Spine 39:185-191, 2014

26. Neen D, Noyes D, Shaw M, Gwilym S, Fairlie N, Birch N: Healos and bone marrow aspirate used for lumbar spine fusion. Spine 31:E636-E640, 2006 
27. Odom GL, Finney W, Woodhall B: Cervical disc lesions. J Am Med Assoc 166:23-28, 1958

28. Oonishi H, Kushitani S, Yasukawa E, Iwaki H, Hench L, Wilson $\mathrm{J}$, et al: Particulate bioglass compared with hydroxyapatite as a bone graft substitute. Clin Orthop Relat Res 334:316-325, 1997

29. Parajón A, Alimi M, Navarro-Ramirez R, Christos P, TorresCampa JM, Moriguchi Y, et al: Minimally invasive transforaminal lumbar interbody fusion: meta-analysis of the fusion rates. What is the optimal graft material? Neurosurgery 81:958-971, 2017

30. Rantakokko J, Frantzén JP, Heinänen J, Kajander S, Kotilainen E, Gullichsen E, et al: Posterolateral spondylodesis using bioactive glass S53P4 and autogenous bone in instrumented unstable lumbar spine burst fractures. Scand J Surg 101:66-71, 2012

31. Saarenpää I, Stoor P, Frantzén J: BAG S53P4 putty as bone graft substitute - a rabbit model. Biomed Glasses 3:30-40, 2017
32. Thaler M, Lachner R, Gstöttner M, Kobel C, Bach C: The use of beta-tricalcium phosphate and bone marrow aspirate as a bone graft substitute in posterior lumbar interbody fusion. Eur Spine J 22:1173-1182, 2013

33. Tokuhashi Y, Ajiro Y, Umezawa N: Subsidence of metal interbody cage after posterior lumbar interbody fusion with pedicle screw fixation. Ortopedics 32:259-264, 2009

34. Vaidya R, Weir R, Sethi A, Meisterling S, Hakeos W, Wybo $\mathrm{CD}$ : Interbody fusion with allograft and rhBMP-2 leads to consistent fusion but early subsidence. J Bone Joint Surg 89-B:342345, 2007

35. Venkataraman N, Bansal S, Bansal P, Narayan S: Dynamics of bone graft healing around implants. J Int Clin Dent Res Organ 7:40-47, 2015

36. Wilson T, Parikka V, Holmblom J, Ylänen H, Penttinen R: Intact surface of bioactive glass S53P4 is resistant to osteoclastic activity. J Biomed Mater Res 77A:67-74, 2006 